\title{
Erratum to: Methods for Molecular Evolution of Polymerases
}

\author{
S. A. Zhukov ${ }^{a, 1}$, S. V. Vasilyeva ${ }^{a, b, 1,2}$, A. A. Fokina ${ }^{a, b}$, and D. A. Stetsenko ${ }^{a, b}$ \\ ${ }^{a}$ Novosibirsk State University, Novosibirsk, 630090 Russia \\ ${ }^{b}$ Institute of Chemical Biology and Fundamental Medicine, Siberian Branch, \\ Russian Academy of Sciences, Novosibirsk, 630090 Russia \\ Submitted March 19, 2020; accepted for publication March 19, 2020
}

DOI: $10.1134 / \mathrm{S} 1068162020040068$

The sequence of authors' names should read as follows:

S. A. Zhukov, S. V. Vasilyeva, A. A. Fokina, and D. A. Stetsenko

The original article can be found online at https://doi.org/10.1134/S1068162019060426

\footnotetext{
${ }^{1}$ The authors contributed equally to the work.

${ }^{2}$ Corresponding author.
} 